\title{
Variations in the thickness of the crust of the Kaapvaal craton, and mantle structure below southern Africa
}

\author{
C. Wright, M. T. O. Kwadiba*, R. E. Simon ${ }^{\dagger}$, E. M. Kgaswane ${ }^{\ddagger}$, and T. K. Nguuri** \\ Bernard Price Institute of Geophysical Research, School of Geosciences, University of the Witwatersrand, Private Bag 3, Wits 2050, South Africa
}

(Received September 17, 2003; Revised March 3, 2004; Accepted March 3, 2004)

\begin{abstract}
Estimates of crustal thicknesses using $P n$ times and receiver functions agree well for the southern part of the Kaapvaal craton, but not for the northern region. The average crustal thicknesses determined from $P n$ times for the northern and southern regions of the craton were $50.52 \pm 0.88 \mathrm{~km}$ and $38.07 \pm 0.85 \mathrm{~km}$ respectively, with corresponding estimates from receiver functions of $43.58 \pm 0.57 \mathrm{~km}$ and $37.58 \pm 0.70 \mathrm{~km}$. The lower values of crustal thicknesses for receiver functions in the north are attributed to variations in composition and metamorphic grade in an underplated, mafic lower crust, resulting in a crust-mantle boundary that yields weak $P$-to- $S V$ conversions. $P$ and $S$ wavespeeds in the uppermost mantle of the central regions of the Kaapvaal craton are high and uniform with average values of 8.35 and $4.81 \mathrm{~km} / \mathrm{s}$ respectively, indicating the presence of depleted magnesium-rich peridotite. The presence of a low wavespeed zone for $S$ waves in the upper mantle between depths of 210 and about $345 \mathrm{~km}$ that is not observed for $P$ waves was inferred outside the Kaapvaal craton. The $410 \mathrm{~km}$ discontinuity shows similar characteristics to that in other continental regions, but occurs slightly deeper at $420 \mathrm{~km}$. There is no evidence for a discontinuity near $520 \mathrm{~km}$ depth. The $660 \mathrm{~km}$ discontinuity also appears to be slightly deeper than average $(668 \mathrm{~km})$, and is poorly defined for $P$ waves, but clear for $S$ waves.
\end{abstract}

Key words: Gondwanaland, Kaapvaal craton, crust and mantle structure.

\section{Introduction}

The Archaean Kaapvaal craton and adjacent Proterozoic mobile belts cover much of southern Africa (Fig. 1). A feasibility study on the use of mine tremors in South Africa for determining crustal structure was pioneered more than fifty years ago by Gane et al. (1946). $P$ and $S$ waves from these mining-induced events were subsequently used to determine the wavespeed structure of the crust and uppermost mantle around the Witwatersrand basin (Willmore et al., 1952; Hales and Sacks, 1959; Durrheim and Green, 1992; Durrheim, 1998). However, only recently have such events been used in conjunction with local and regional tectonic events to determine regional travel-time curves and earth structure from the surface to depths of $800 \mathrm{~km}$ (Simon et al., 2002, 2003; Wright et al., 2002).

There have been few seismological studies of earth structure within southern Africa compared with many other areas of the world such as Australia, North America and western Europe, so that there is a need for better definition of the structure of the underlying crust and mantle to understand

\footnotetext{
*Also at Department of Geological Survey, Private Bag 14, Lobatse, Botswana.

${ }^{\dagger}$ Present Address: Department of Physics, University of Botswana, Private Bag UB704, Gaborone, Botswana.

$\ddagger$ Present Address: Council for Geoscience, Private Bag X112, Pretoria 0001, South Africa.

** Present Address: PREPCOM CTBTO, Vienna International Centre, P.O. Box 1250, A-1400, Vienna, Austria.
}

Copy right (C) The Society of Geomagnetism and Earth, Planetary and Space Sciences (SGEPSS); The Seismological Society of Japan; The Volcanological Society of Japan; The Geodetic Society of Japan; The Japanese Society for Planetary Sciences; TERRAPUB cratonic evolution and to enable earthquakes to be more accurately located. Between April 1997 and April 1999, a network of broad-band seismic instruments was deployed across southern Africa (Carlson et al., 1996) as part of the international Kaapvaal craton programme (Fig. 1). The main objective of this seismic experiment was to derive tomographic images of the crust and mantle to depths of about $1000 \mathrm{~km}$ using recordings of teleseismic earthquakes (i.e. earthquakes at distances greater than $3300 \mathrm{~km}$ ) (James et al., 2001). However, the network also recorded local (distances less than $300 \mathrm{~km}$ ) and regional earthquakes (distances between 300 and $3300 \mathrm{~km}$ ), thus enabling more detailed information on the seismicity of southern Africa to be obtained over a 25-month period. The seismicity of South Africa is dominated by mining-induced events on the margin of the Witwatersrand basin, which, because of accurate locations (epicentres and focal depths with errors less than 400 and $500 \mathrm{~m}$ respectively), provide excellent information on earth structure (Kgaswane et al., 2002).

The seismological structure of the upper mantle and transition zone below southern Africa has recently been studied by several different methods (Freybourger et al., 2001; James et al., 2001; Silver et al., 2001; Stankiewicz et al., 2002). The present work uses a different approach: the use of travel times and waveforms of $P$ and $S$ arrivals (Walck, 1984; Ryberg et al., 1998).

The high density of seismic stations of the Kaapvaal craton broad-band network (Carlson et al., 1996) enables the average body wavespeed structure beneath southern Africa to be reliably defined. The present work builds on earlier studies of the mantle below southern Africa (Bloch et al., 1969; 


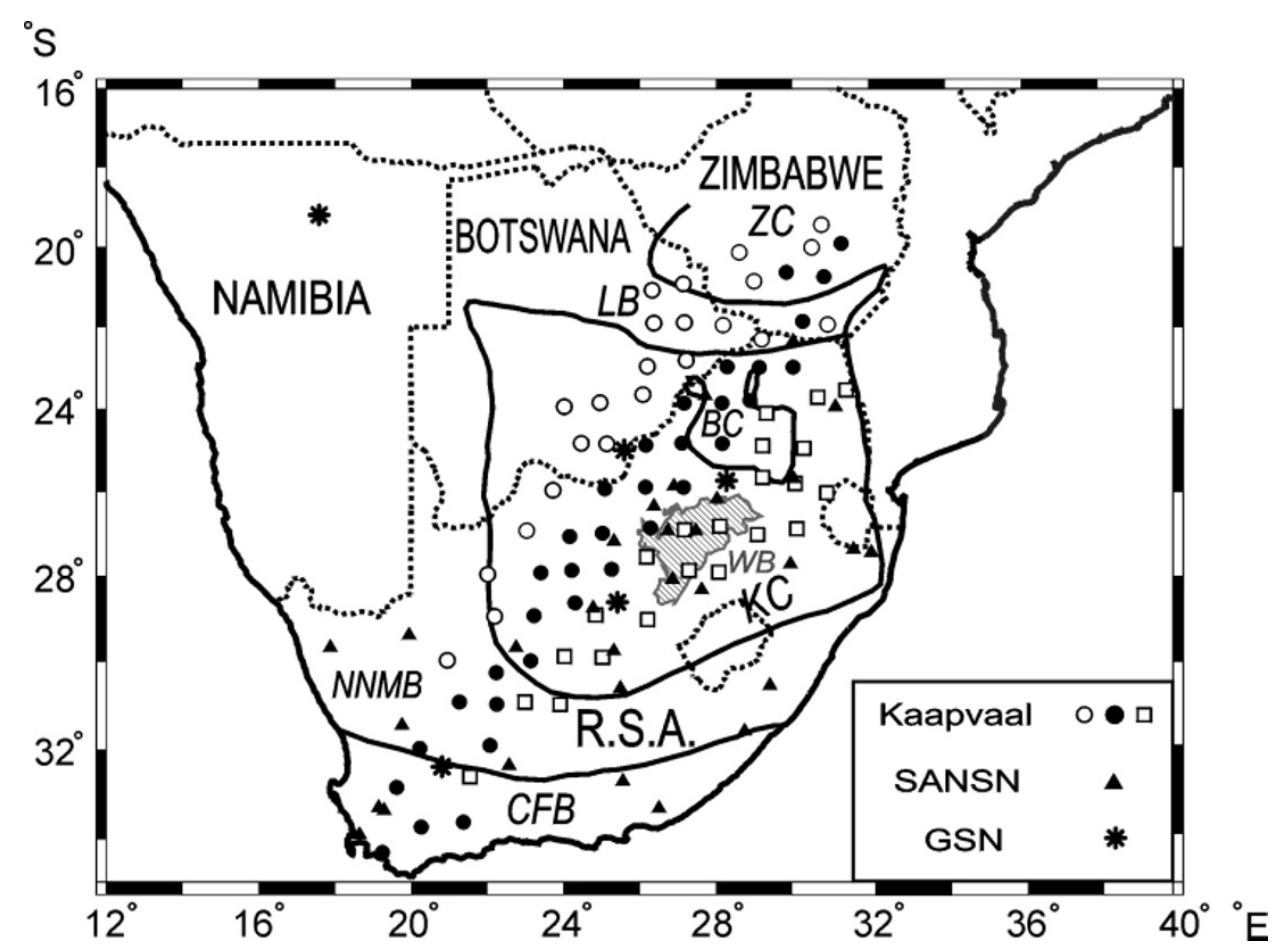

Fig. 1. Map of southern Africa showing distribution of stations of the Kaapvaal broad-band seismic experiment superimposed on the major crustal blocks of southern Africa (after Simon et al., 2002). BC-Outer boundary of surface outcrops of Bushveld complex; CFB-Cape Fold belt; LB-Limpopo belt; NNMB-Namaqua Natal mobile belt; WB-Witwatersrand basin; ZC-Zimbabwe craton. Open and closed circles and squares denote stations of the Kaapvaal broad-band network that operated from April 1997-April 1998, April 1997-April 1999 and April 1998-April 1999, respectively. Triangles denote stations of the South African national network (SANSN), and asterisks broad-band stations of the Global Seismological Network (GSN) or permanent long-period stations.

Cichowicz and Green, 1992; Qiu et al., 1996; Zhao et al., 1999) by improving resolution of deep-seated structures and extending models to depths of $800 \mathrm{~km}$. We compare the $P$ wavespeed results with the preferred model (SATZ) of Zhao et al. (1999) because it was derived using a similar kind of data for a region just to the north of the present study area. The GNEM model (Generalised Northern Eurasia Model) of Ryberg et al. (1998) for northern Eurasia allows a comparison with the upper mantle and transition zone below a region in a different continent. The $S$ wavespeed model is compared with that of the model for southern Africa derived from surface waves (Qiu et al., 1996) and with those from other parts of Gondwanaland (Dey et al., 1993; Kennett et al., 1994; Kaiho and Kennett, 2000). A comparison with the IASP91 models for $P$ and $S$ waves of Kennett (1991) is also provided, since they are modern reference wavespeed models in which the upper mantle components are weighted by data from both oceanic and continental regions.

There are four main objectives of the present study. The first is to determine whether or not there are regional variations in the seismic $P$ and $S$ wavespeeds within the uppermost mantle, and to define variations in crustal thicknesses beneath the Kaapvaal craton using $P n$ arrivals from mininginduced earthquakes. Comparison of the results with those from receiver functions (Nguuri et al., 2001) provides complementary information on the structure and properties of the lower crust and uppermost mantle. Therefore, the second objective is to compare crustal thicknesses estimated using receiver functions and refracted arrivals to assist better understanding the seismic properties and petrology of the lower crust. The results can then be used to define starting models for tomographic inversion for the structure of the crust and uppermost mantle of the Kaapvaal craton and surrounding regions.

The final two objectives concern mantle structure. The first is to derive average $P$ and $S$ wavespeed models beneath southern Africa from the surface to depths of $800 \mathrm{~km}$. The second is to identify any unusual features that might provide distinctive information on composition. The paper brings together recent seismological results from the Kaapvaal craton and adjacent regions, emphasizing the newest results.

\section{Data Acquisition and Geological Setting}

Data used in this study are from local and regional earthquakes and mining-induced tremors recorded by the Kaapvaal network, supplemented by arrival times measured at the South African national seismic network (SANSN) at distances less than $10^{\circ}$ (Fig. 1) (Wright et al., 2002). The Kaapvaal network consisted of 84 broad-band stations deployed across southern Africa over a 25-month period from April 1997 until April 1999, with over fifty stations in operation at a given time (Carlson et al., 1996; Simon et al., 2002). The broad-band sensors formed a grid network with an average spacing of about $100 \mathrm{~km}$. Permanent broad-band or longperiod stations (shown as asterisks), which augmented the data from the Kaapvaal network, and the stations of SANSN are also plotted in Fig. 1.

Figure 1 shows the most important tectonic elements of southern Africa (de Wit et al., 1992). The Archaean Zimbabwe and Kaapvaal cratons are separated by the late Ar- 
chaean Limpopo belt. The curves labelled BC define the outer limits of the surface outcrops of the mafic intrusions of the Bushveld complex emplaced at 2.05 Ga (Eales, 2001). South of the Kaapvaal craton is the Proterozoic NamaquaNatal mobile belt, and the Mesozoic Cape fold belt. The late Archaean Witwatersrand basin, which hosts South Africa's major gold deposits, and provides abundant induced seismicity (Kgaswane et al., 2002), is situated in the central regions of the Kaapvaal craton. The Lebombo monocline (not shown in Fig. 1) associated with the Mesozoic splitting of Gondwanaland forms the eastern margin of the Kaapvaal craton (de Wit et al., 1992).

\section{Data Selection}

The strategy in this work was to construct regional $P$ and $S$ travel-time curves to distances of $20^{\circ}$ to assist improved earthquake locations, and then to determine an average structure of the crust and uppermost mantle to depths of $320 \mathrm{~km}$ (Kgaswane et al., 2002; Wright et al., 2002). The data used were $P$ and $S$ travel times from local, regional and mininginduced earthquakes, recorded at both the Kaapvaal network and SANSN. The next step was to determine the structure of the upper mantle below $320 \mathrm{~km}$ depth, the transition zone and uppermost lower mantle to depths of about $800 \mathrm{~km}$. This was achieved through selection of broad-band seismograms of regional earthquakes at distances up to $34^{\circ}$ having magnitudes greater than 5, recorded at both the Kaapvaal network and permanent broad-band stations in the region (Fig. 1). 15 of the largest of these were used to determine both $P$ and $S$ wave structure, and are plotted in Fig. 2.

There are many mining-induced earthquakes that can be used to determine the structure of the crust and uppermost mantle, but very few located tectonic earthquakes. In principle, this enormous quantity of data can be used to define lateral variations in the thickness of the crust and upper mantle wavespeeds in the central regions of the Kaapvaal craton. However, these seismic events are concentrated in three main areas of a few hundred square kilometres, giving a far from ideal situation for reliable determination of structure. Even the use of a simple approach such as the time-term method (Willmore and Bancroft, 1960) cannot be used. Nevertheless, some important constraints can be placed on crustal thicknesses and upper mantle wavespeeds, which provide starting models for the crustal tomography. Comparison with the results from receiver functions also yields information on the properties of the lower crust.

The data consist of seismograms from 60 mining-induced tremors recorded by stations of the Kaapvaal network: 20 in each of the Far West and West Rand, Klerksdorp and Welkom areas (most western three asterisks of Fig. 2). Events with local magnitudes greater than 3 were used to ensure reasonably strong arrivals to distances of at least $700 \mathrm{~km}$. Epicentres were obtained from mine catalogues (Kgaswane et al., 2002). Origin times were derived from the Council for Geoscience earthquake bulletins Graham (1997, 1998, 1999), and corrected by the methods described by Wright et al. (2002, 2003). For time picking of first arrivals ( $P g$ or $P n$ and $S g$ or $S n$ ), all seismograms were bandpassfiltered between 0.4 and $4.0 \mathrm{~Hz}$ and 0.2 and $2.0 \mathrm{~Hz}$, respectively.

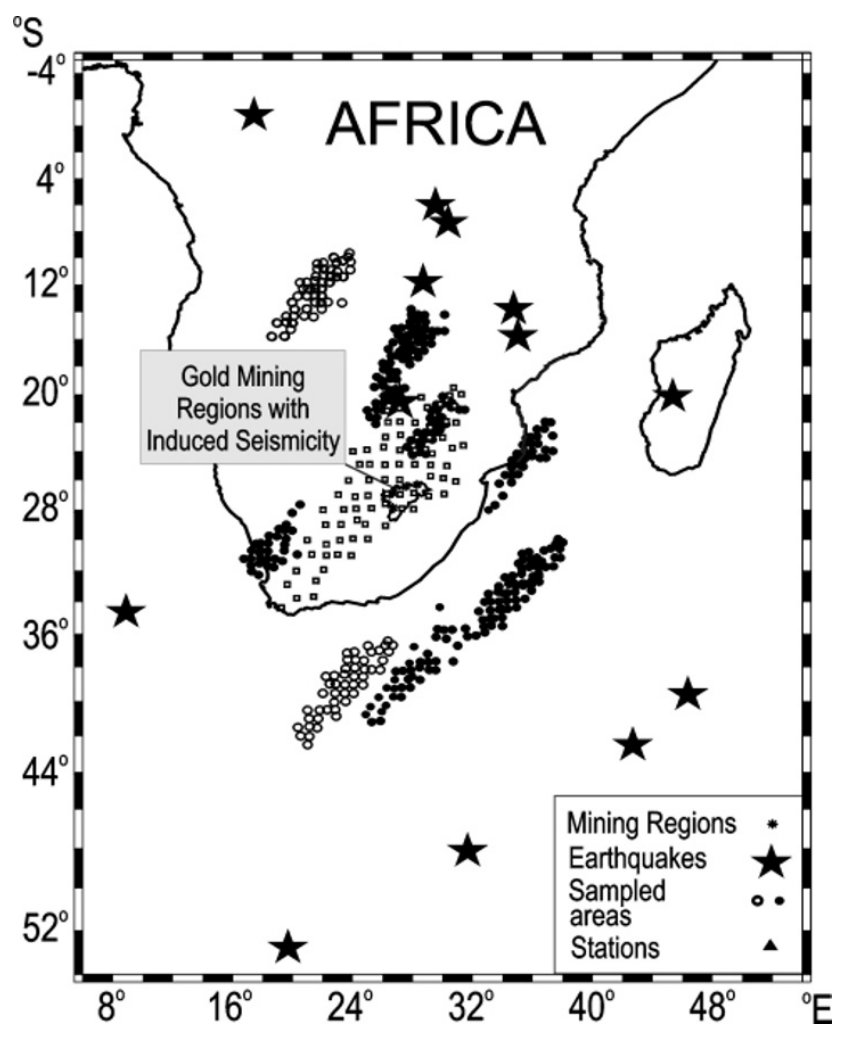

Fig. 2. Map showing locations of mine tremors and earthquakes used in this study (modified from Simon et al., 2002). The four small asterisks show the main areas of mining-induced seismicity: from bottom to top-Welkom, Klerksdorp, Far West and West Rand, Central and East Rand. The map shows big stars, squares, closed circles and open circles denoting earthquake sources, Kaapvaal network station locations, sampled areas above and within the transition zone, and sampled areas below the transition zone, respectively. The circles define the mid-points between sources and stations.

The map of Fig. 3 shows the Kaapvaal network and the main tectonic elements. A circle is shown with the Klerksdorp mining area as the centre. The $P n$ times were divided into nine azimuthal sectors R1 to R9 and average $P n$ wavespeeds calculated to determine if there were azimuthal variations. Since there are no known changes in crustal thickness as a function of distance of the $P n$ arrivals, the estimated average wavespeeds should not be seriously biased. Each azimuthal sector overlaps its successor. For example, region 5, shown as the shaded sector, runs from the radius marked R5 to that marked R7. There are few stations between east and south of the sources.

\section{Data Analysis and Results \\ 4.1 Crust and uppermost mantle}

If the $P n$ times used are confined to stations within the Kaapvaal craton, there is little change in $P n$ wavespeed as a function of azimuth. As the azimuths change, we also find that there is an abrupt increase in travel times of $P n$ and $S n$ to the north of the thick line in Fig. 3 that divides the Kaapvaal craton into two regions. This line forms the boundary between the southern part of the craton that has not been subjected to major tectonism since the Archaean, and the northern regions affected by the Bushveld magmatic event at $2.05 \mathrm{Ga}$. 


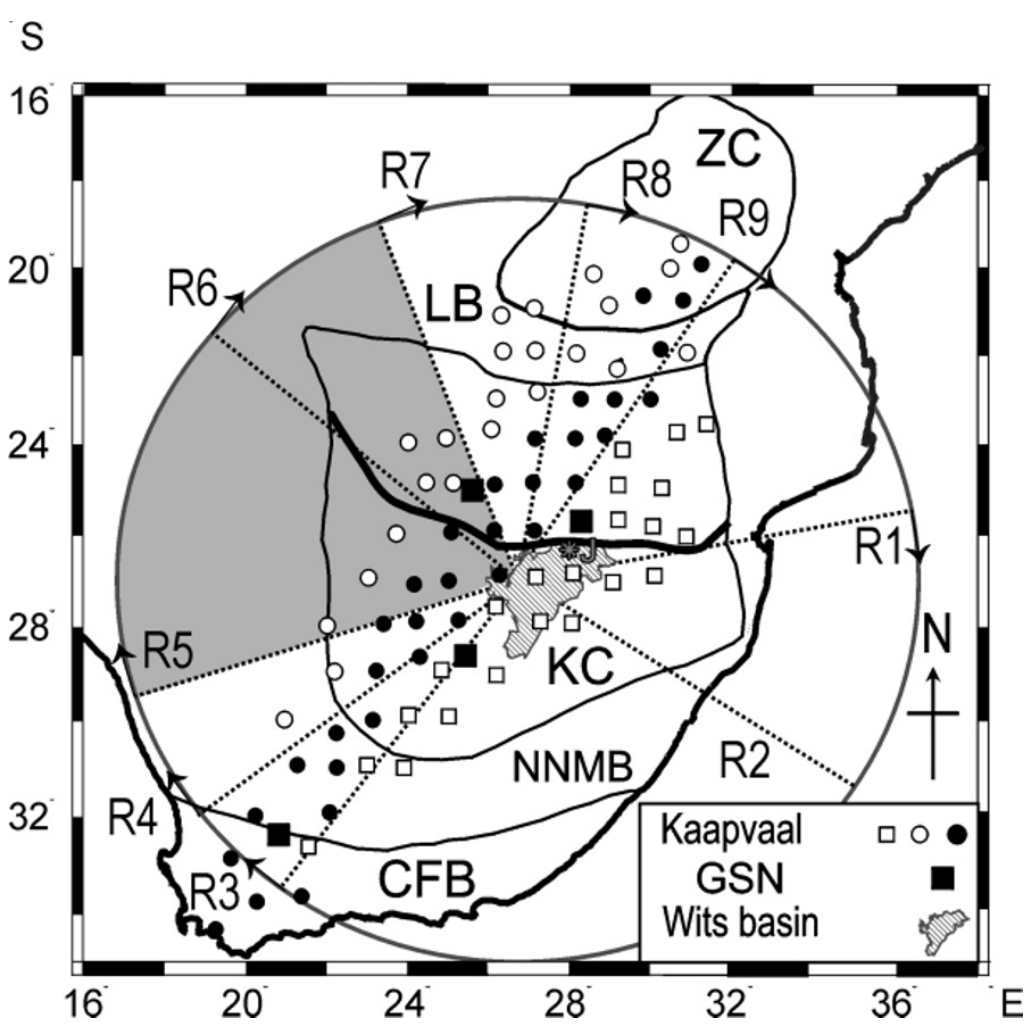

Fig. 3. Map showing subdivision of the Kaapvaal craton region into nine overlapping azimuth ranges for the Klerksdorp region, and division of craton into northern and southern regions (thick black line). Each azimuth range comprises the segment clockwise from the numbered arrow through the start of the next range to the start of following range. Open circles, closed circles and open squares denote stations of the Kaapvaal network that operated from April 1997-April 1998, April 1997-April 1999 and April 1998-April 1999, respectively. Closed squares denote permanent broad-band or long-period stations. Wits basin is short for Witwatersrand basin. Other abbreviations have the same meaning as those in Fig. 1.

Table 1. Results of fitting regression lines through the $P n$ data for 20 events in each of the three most active source regions. Results are also shown for $S n$ from 8 events from all three regions.

\begin{tabular}{|c|c|c|c|c|c|}
\hline Phase & Station & Source & No. of & $\mathrm{V}, \mathrm{km} / \mathrm{s}^{*}$ & Intercept, s \\
Region & Region & Times & & \\
\hline$P n$ & North & FWR & 205 & $8.333 \pm 0.032$ & $9.29 \pm 0.15$ \\
\hline$P n$ & North & KLE & 204 & $8.415 \pm 0.027$ & $9.18 \pm 0.12$ \\
\hline$P n$ & South & FWR & 249 & $8.308 \pm 0.020$ & $8.14 \pm 0.12$ \\
\hline$P n$ & South & KLE & 209 & $8.305 \pm 0.029$ & $7.66 \pm 0.16$ \\
\hline$P n$ & South & WEL & 262 & $8.313 \pm 0.032$ & $8.00 \pm 0.16$ \\
\hline$S n$ & North & All regions & 50 & $4.796 \pm 0.030$ & $16.15 \pm 0.48$ \\
\hline$S n$ & South & All regions & 58 & $4.827 \pm 0.035$ & $14.34 \pm 0.57$ \\
\hline
\end{tabular}

FWR - Far West Rand and West Rand; KLE - Klerksdorp; WEL - Welkom. * - corrected for curvature of Earth.

Table 1 shows the results of fitting regression lines through the $P n$ data for 20 events in each of the three most active source regions. Results are also shown for $S n$ from 8 events from all three regions. The calculations show that the upper mantle wavespeeds for $P$ and $S$ are high, averaging about 8.35 and $4.81 \mathrm{~km} / \mathrm{s}$. Such high wavespeeds are indicative of highly depleted magnesium-rich peridotites in the subcratonic uppermost mantle. Furthermore, these wavespeeds are significantly higher by about 0.11 and $0.13 \mathrm{~km} / \mathrm{s}$ respectively than those estimated from peridotite xenoliths found in kimberlite pipes within the craton, even allowing for differences in temperature and pressure (Ben-Ismail et al., 2001). There are larger intercept times of about $1.3 \mathrm{~s}$ and $1.8 \mathrm{~s}$ for $P n$ and $S n$ respectively for northern stations, indicating that the crust is much thicker beneath these stations than below the southern stations.

Figure 4 shows the first arrival times from 20 events in the Far West and West Rand regions with $\mathrm{M}_{L}>3$, plotted as reduced time against distance. Times to stations in the northern and southern regions are denoted by open and closed squares respectively. Regression lines through the two sets of $P n$ times at stations that lie within the Kaapvaal craton are shown as grey (north) and black (south) lines respectively. These lines are almost parallel, and separated by about 1.3 s. Both lines have been terminated at the craton margins. A similar pattern of times was found for events from Klerksdorp and Welkom, and for the $S$ wave arrivals. The sharp offset in reduced travel times at distances of around $700 \mathrm{~km}$ for southern stations that are beyond the edge of the craton is most probably due to both an increase in crustal thickness in the Namqua-Natal mobile belt (Fig. 1) identified by receiver functions (Nguuri et al., 2001) and a reduction in seismic 


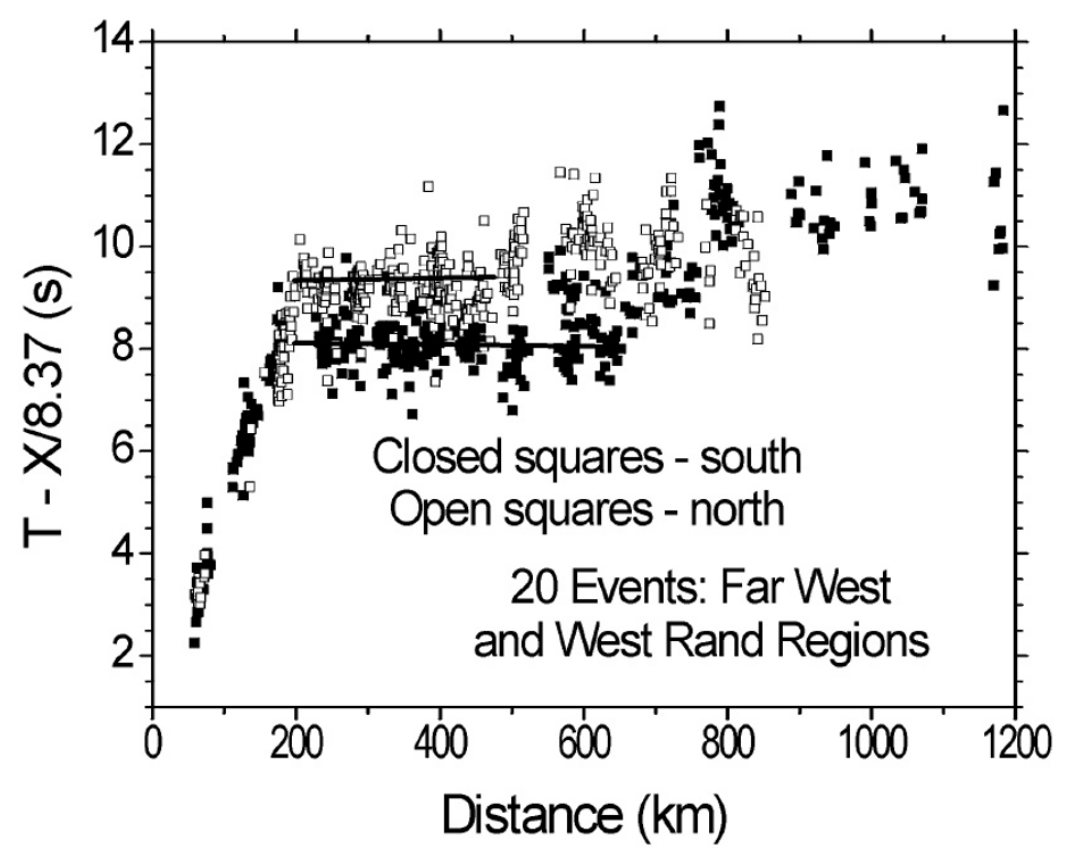

Fig. 4. $P g$ and $P n$ times for 20 events in the Far West and West Rand regions. Open and closed squares denote times measured at stations to the north of the thick line in Fig. 3. Regression lines through the $P n$ times at stations within the Kaapvaal craton are shown as grey (north) and black (south) lines respectively.

Receiver Functions

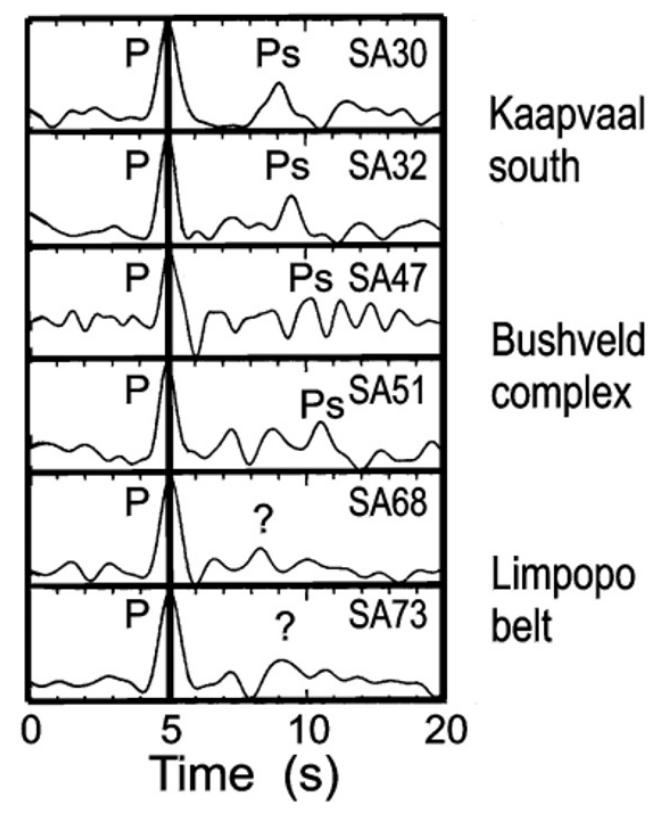

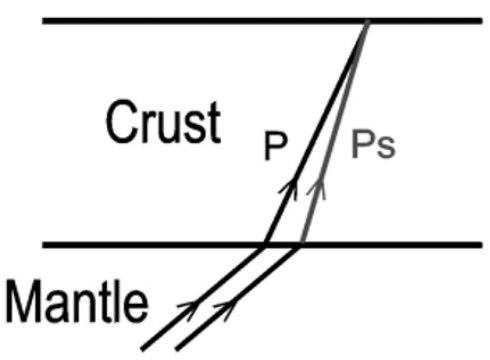

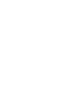


Table 2. A summary of a comparison between estimates of crustal thicknesses from receiver functions and from $P n$ arrivals for the Kaapvaal craton.

\begin{tabular}{|c|c|c|c|}
\hline Method & Region & Comments & $\begin{array}{c}\text { Average } \\
\text { Thickness of } \\
\text { Crust, km }\end{array}$ \\
\hline \multirow[t]{2}{*}{$\begin{array}{l}\text { Receiver } \\
\text { functions }\end{array}$} & $\begin{array}{l}\text { Witwatersrand basin, } \\
\text { close to areas of gold } \\
\text { mining }\end{array}$ & & 42.0 \\
\hline & $\begin{array}{l}\text { Far West and West } \\
\text { Rand mining areas }\end{array}$ & $\begin{array}{l}\text { Value fixed to be consistent } \\
\text { with receiver functions }\end{array}$ & 43.0 \\
\hline$P n$ times & Klerksdorp mining area & $\begin{array}{l}\text { Statistical estimate from } \\
\text { differences in times from Far } \\
\text { West and West Rand regions } \\
\qquad(-2.5 \pm 0.30 \mathrm{~km})\end{array}$ & 40.5 \\
\hline \multirow[t]{2}{*}{$P n$ times } & Welkom mining area & $\begin{array}{c}\text { Statistical estimate from } \\
\text { differences in times from Far } \\
\text { West and West Rand regions } \\
(-2.2 \pm 0.35 \mathrm{~km})\end{array}$ & 40.8 \\
\hline & & $\begin{array}{c}\text { Average Thickness of } \\
\text { Crust, km }\end{array}$ & $\begin{array}{l}\text { No. of } \\
\text { Stations }\end{array}$ \\
\hline$P n$ times & Kaapvaal craton south & $38.07 \pm 0.85$ & 19 \\
\hline $\begin{array}{l}\text { Receiver } \\
\text { functions }\end{array}$ & Kaapvaal craton south & $37.58 \pm 0.70$ & 19 \\
\hline$P n$ times & Kaapvaal craton north & $50.52 \pm 0.88$ & 19 \\
\hline $\begin{array}{l}\text { Receiver } \\
\text { functions }\end{array}$ & Kaapvaal craton north & $43.58 \pm 0.57$ & 19 \\
\hline
\end{tabular}

Table 3. Summary of approach to data analysis.

\section{Sequence of Steps Used in Deriving $P$ and $S$ Wavespeed Models}

1. Assemble $\mathrm{P}$ and $\mathrm{S}$ times for mining-induced tremors and local and regional earthquakes from distances of 0 to $34^{\circ}$.

2. Correct $\mathrm{P}$ and $\mathrm{S}$ times for relative origin time errors using a damped leastsquares inversion on $\mathrm{P}$ times.

3. Adjust all origin times by using a reference crustal model to ensure that the inferred travel times are zero at zero distance.

4. Construct preliminary smooth wavespeed models by ray tracing and HerglotzWiechert inversion.

5. Identify later arrivals due to mantle discontinuities visually or through phaseweighted stacking, and refine models by matching results with synthetic seismograms (WKBJ method).

6. Check refined model by ray tracing to compare with original times, and make final adjustments. 


\section{Time - D/10.0 (s)}
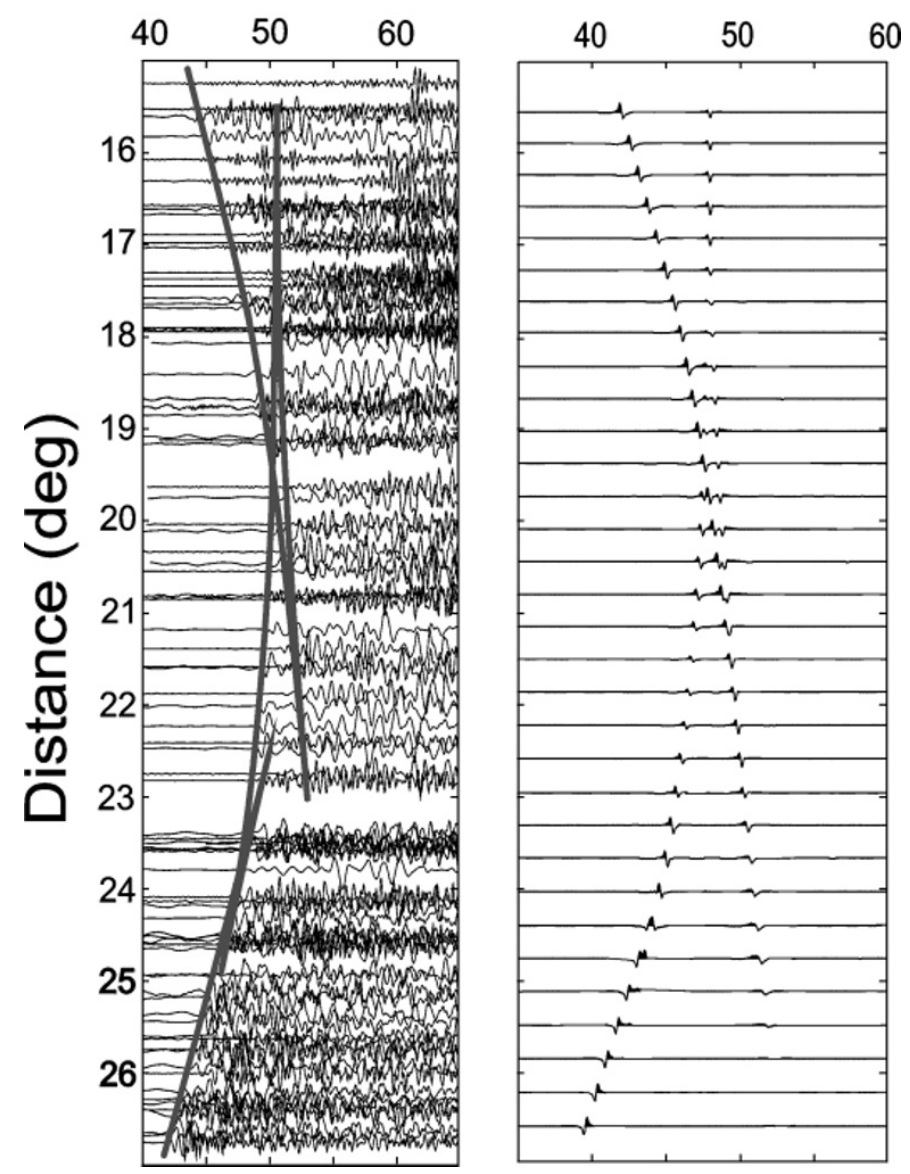

Fig. 6. (a) Composite record section of vertical-component $P$ waveforms from six events mainly to the north of the Kaapvaal network (Fig. 2), from Simon et al. (2002). The waveforms were bandpass-filtered from $0.4-4.0 \mathrm{~Hz}$ and are overlain with the reduced travel-time curve from the final model BPI1A. (b) Synthetic seismograms produced by the WKBJ method using model BPI1A, and bandpass-filtered between 0.4 and $4.0 \mathrm{~Hz}$.

mantle and crust labelled $P$. The $P$ arrival will be followed by an arrival denoted $P S$ in which some of the $P$ wave energy arriving at a sharp crust-mantle boundary has been converted to $S V$ waves. Because of the slower $S$ wavespeeds, the $P s$ energy travels steeper paths to the surface. The measured time difference between the $P s$ and $P$ arrivals in conjunction with assumed $P$ and $S$ wavespeed variations in the crust and uppermost mantle yield estimates of crustal thickness (Ammon, 1991), which, for stations of the Kaapvaal network were published by Nguuri et al. (2001).

Important information comes from comparing the crustal thicknesses estimated from receiver functions and from refracted arrivals. Receiver functions at stations within or very close to the margins of the Witwatersrand basin, close to the earthquake sources (Fig. 2), yield an average value $\mathrm{H}_{c}$ of 42 km (Wright et al., 2003).

Crustal thicknesses for the central parts of the Kaapvaal craton were estimated from $P n$ arrivals using a method described by Kwadiba et al. (2003). By fixing the crustal thickness for one region, the Far West and West Rand, at 43.0 $\mathrm{km}$, a statistical analysis of $P n$ times assisted by ray tracing yielded estimates of the relative crustal thicknesses below the other two main source regions. These thicknesses were 40.5 and $40.8 \mathrm{~km}$ for Klerksdorp and Welkom, respec- tively. Using these thicknesses for each source region, the thicknesses of the crust were estimated below 19 centrally located stations in the southern part of the Kaapvaal craton. The agreement with the values for receiver functions was good (Kwadiba et al., 2003), and the average values for $P n$ and receiver functions were 38.1 and $37.6 \mathrm{~km}$ respectively (Table 2).

When the same procedure is applied to 19 stations in the northern part of the Kaapvaal craton within or close to the Bushveld complex, the $P n$ arrivals yield an average thickness of $50.5 \mathrm{~km}$, compared with $43.6 \mathrm{~km}$ for the receiver functions: a difference of about $7 \mathrm{~km}$. A possible explanation is that the upper mantle wavespeeds in the north have been overestimated, thereby underestimating the travel times in the mantle, which will be compensated by overestimates of the times to travel through the crust. However, we find no evidence to support this alternative explanation. $S n$ arrivals give a similar result to $P n$.

\subsection{Upper mantle and transition zone}

4.2.1 Properties of data Table 3 summarises how the data were prepared and analysed, and the methods were described by Simon et al. (2003) and Wright et al. (2003). An important purpose of the present work is to identify rapid increases in seismic wavespeeds or wavespeed gradients that 


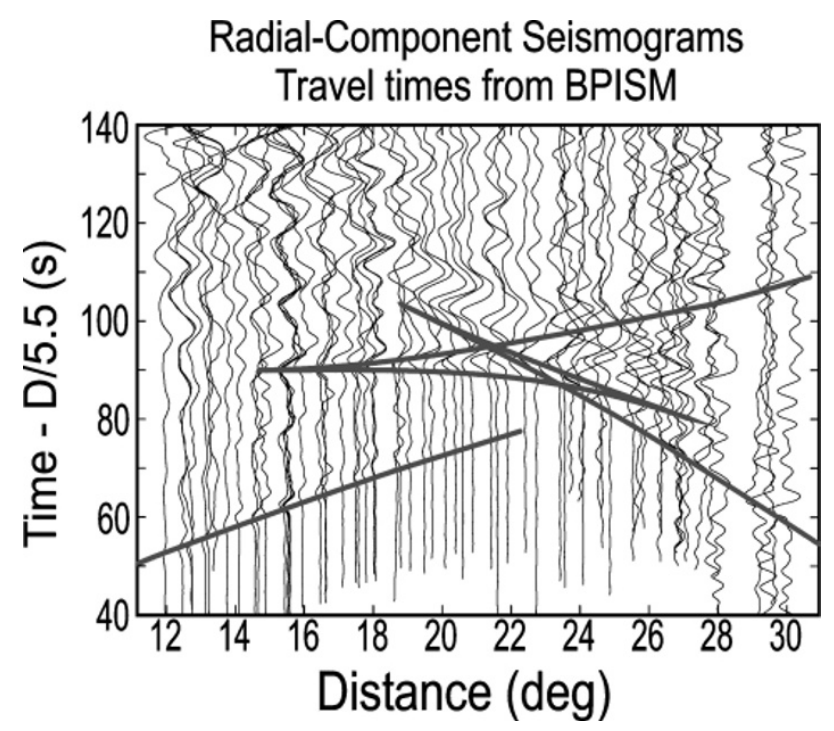

Fig. 7. Composite record section of radial-component waveforms from the same earthquakes as the vertical-component seismograms of Fig. 6. The waveforms have been bandpass-filtered from $0.2-2.0 \mathrm{~Hz}$ and overlain with the reduced travel-time curve from model BPISM $\left(V_{\text {red }}=5.5 \mathrm{~km} / \mathrm{s}\right)$.

may be associated with major changes in composition, or with phase transformations in which some minerals present in the earth's mantle form more densely-packed structures that are stable at higher pressures. A discontinuous increase in wavespeed produces a triplication in travel times. The interpretation of seismograms is complicated by the difficulty of identifying travel-time branches of a triplication that follow the earliest arrival, because of the presence of signalgenerated-noise that usually masks the later arrivals. An important part of the present research was to use signalprocessing techniques that suppress signal-generated-noise, thereby allowing the identification of the later branches of triplications, which in turn enables reliable constraints to be placed on the changes in wavespeed around the discontinuity. Despite the relatively sparse spatial sampling, this can be accomplished through phase-weighted stacking, which suppresses incoherent noise (Schimmel and Paulssen, 1997; Simon et al., 2002). The $P$ and $S$ wave models were then refined by matching results with synthetic seismograms calculated by the WKBJ method (Chapman, 1978). The final stage in the analysis was to check the refined models by ray tracing to compare with the original times and make final adjustments (Table 3).

For observations at short distances (shallow depths), the resulting wavespeed model is representative of the crust and uppermost mantle in the central parts of the Kaapvaal craton around the Witwatersrand basin. The models are predominantly cratonic to depths well below $100 \mathrm{~km}$, but as the depth increases further, the input data contain more information from outside the craton. By $200 \mathrm{~km}$ depth, the mid-points of the source-station paths, which tell us the approximate locations of structure, lie outside the margins of the craton in the adjacent mobile belts (Fig. 1). At greater depths, since there are insufficient data to reliably resolve lateral variations, structure is averaged over a wider and wider region. The concept of averaging over a progressively wider region is illustrated in Fig. 2, in which the closed circles show mid points for signals which travel within the transition zone and reach the stations as first arrivals, while open circles denote signals that have passed through the uppermost lower mantle. Resolution of lateral variations becomes more difficult as the depth increases. While we can detect small differences in travel-time slopes between earthquakes on the continent and below the oceans, more data would be required for effective quantitative analysis of lateral variations in the deeper parts of the upper mantle and transition zone.

4.2.2 Illustrative Record Sections Seismograms from six earthquakes north of the Kaapvaal network are displayed at distances between $15^{\circ}$ and $27^{\circ}$, after application of origin-time corrections (Simon et al., 2002) and bandpass filtering between 0.4 and $4.0 \mathrm{~Hz}$ (Fig. 6). Reduced times have been plotted as y coordinates. Also shown are synthetic seismograms for the same range of distances (Chapman, 1978). The travel-time curve for the final $P$ model is shown in grey. There is a prominent triplication associated with the $410 \mathrm{~km}$ discontinuity and a small, poorly-defined triplication associated with the $660 \mathrm{~km}$ discontinuity. For each triplication, the later arrivals are not obvious in the seismograms, and their existence has been inferred using the phase-weighted stack (Schimmel and Paulssen, 1997) to suppress incoherent energy (Simon et al., 2002; Simon, 2003).

Figure 7 shows radial-component seismograms for the same earthquakes as the vertical-component seismograms shown in Fig. 6, bandpass-filtered between 0.2 and $2.0 \mathrm{~Hz}$, and plotted as reduced times. These $S$ wave arrivals show no evidence of $P$ wave precursors due to $S V$-to- $P$ conversions at the crust-mantle boundary or other shallow discontinuities, and are generally clearer than the corresponding transverse components (Simon, 2003). No systematic differences between times measured on the radial and transverse components were detected, so that there is no evidence for anisotropy in the mantle. The lines show the travel-time curves from the final model. The most remarkable feature of the seismograms is the decrease in amplitude beyond $18^{\circ}$ of the first arrival branch, corresponding to energy travelling in the upper mantle above $200 \mathrm{~km}$ depth. At a distance of $22^{\circ}$ no energy associated with this branch of the travel-time curve can be detected. This is evidence for a low wavespeed zone in the upper mantle (Simon, 2003). Phase-weighted stacking shows the presence of a $410 \mathrm{~km}$ discontinuity, and a $660 \mathrm{~km}$ discontinuity that produces a much more prominent triplication than its $P$ wave counterpart.

\section{Interpretation}

\subsection{Crust and uppermost mantle}

Both receiver functions and refracted arrivals from the mantle $(P n$ and $S n)$ show that the crust is thicker in the northern part of the Kaapvaal craton. However, the refracted arrivals and receiver functions provide similar thicknesses in the southern part of the craton, but different thicknesses in the north. A possible explanation of the systematically greater thicknesses of the crust estimated by $P n$ arrivals for the northern part of the Kaapvaal craton is shown schematically in Fig. 8, which is merely a cartoon to illustrate the concepts. In the southern part of the craton, the receiver 


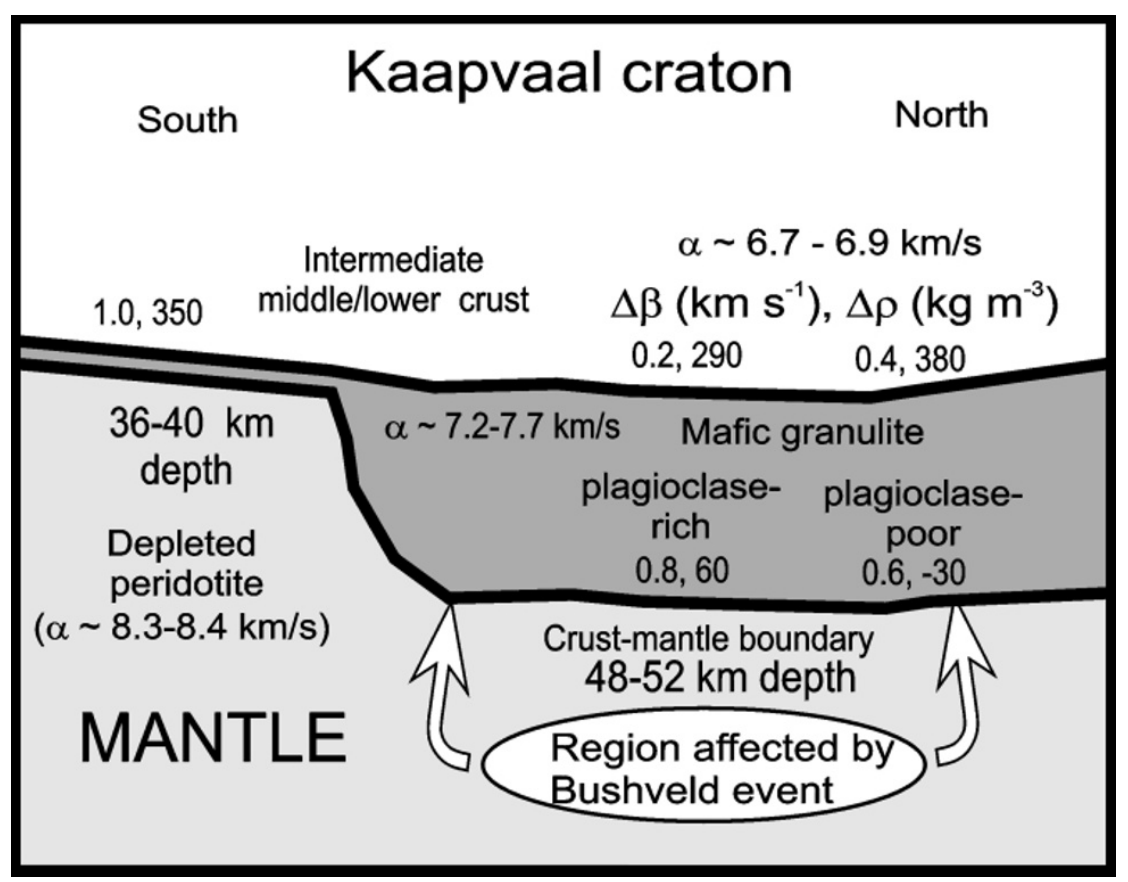

Fig. 8. Schematic diagram to provide a possible explanation for the increase in thickness of the crust in the northern part of the Kaapvaal craton, and the larger increase inferred from $P n$ and $S n$ arrivals compared with receiver functions. The number pairs are approximate changes in shear wavespeed and density in $\mathrm{km} / \mathrm{s}$ and $\mathrm{kg} / \mathrm{m}^{3}$ at the crust-mantle boundary, or the boundary between intermediate middle crust and lower mafic lower crust resulting from underplating.

functions show clear $P s$ conversions (Fig. 5), indicating a sharp crust-mantle boundary. This is satisfactorily explained as a boundary between intermediate granulites and depleted peridotites (Nguuri et al., 2001). The amplitudes of $P s$ conversions depend most strongly on the change in $S$ wavespeed at the boundary. The northern part of the Kaapvaal craton was affected by the Bushveld event at $2.05 \mathrm{Ga}$ (Eales, 2001), which resulted in mafic intrusions that have been mapped over a wide area, and host important deposits of platinum and other valuable metals. The values of the $P$ wavespeed in the uppermost mantle $(8.3-8.4 \mathrm{~km} / \mathrm{s})$ in Fig. 8 are taken from Table 1 . However, all other $P$ and $S$ wavespeeds and densities are estimates based on laboratory estimates on rocks from other parts of the world published by Rudnick and Fountain (1995) and Hurich et al. (2001).

The changes in $S$ wavespeed and density, $\Delta \beta$ and $\Delta \rho$ are approximate, since a broad range of possibilities exist for each rock type (Fig. 8). In the southern part of the craton, changes in $S$ wavespeed and density are roughly $1.0 \mathrm{~km} / \mathrm{s}$ and $350 \mathrm{~kg} / \mathrm{m}^{3}$ respectively. Now consider the lower crust in the region affected by the Bushveld magmatism, where underplating has almost certainly occurred (Nguuri et al., 2001). This underplated material is probably mafic granulite. The seismic properties of mafic rocks can vary quite considerably with composition and metamorphic grade under lower crustal conditions (Hurich et al., 2001). A boundary between intermediate granulite and plagioclase-rich mafic granulite will result in a small change in $S$ wavespeed and a relatively large change in density. At the crust-mantle boundary, however, there will be a large change in $S$ wavespeed with a relatively small change in density. In contrast, plagioclasepoor mafic granulites have seismic properties closer to mantle peridotites. In this situation, the changes in $S$ wavespeed at the top and bottom of the underplated zone may be similar or even larger at the top. The lower crust below the Bushveld complex is likely to be petrologically complicated, but of mafic composition on average, with relatively sharp boundaries at the top and bottom of the underplated region. Receiver functions may therefore be influenced in a complex manner by a predominantly mafic lower crust, and may not yield reliable estimates of crustal thicknesses.

The azimuthal variation of seismic wavespeed has been examined for $P n$ times, and the result is shown in Fig. 9. A black curve has been plotted where there are sufficient data, and a grey curve where the data are sparse. There is a maximum of $8.40 \mathrm{~km} / \mathrm{s}$ at an azimuth of about $15^{\circ}$, and a minimum of $8.25 \mathrm{~km} / \mathrm{s}$ in a roughly east-west direction. All we can say is that the results are consistent with the presence of azimuthal anisotropy, since the wave paths are radiating outwards from the Witwatersrand basin like the spokes of a wheel, and we have no criss-crossing paths. The direction of maximum wavespeed does, however, agree reasonably well with that inferred by Silver et al. (2001) from shear-wave splitting for a greater thickness of mantle rocks below the western and central parts of the craton.

\section{6. $\quad P$ and $S$ Models for Upper Mantle and Transition Zone}

Figure 10 shows the resulting $P$ and $S$ wave models BPI1A and BPISM on the left and right, respectively. Three other $P$ wave models are shown for comparison. The generalized northern Eurasian model, GNEM, of Ryberg et al. (1998) and the IASP91 model (Kennett, 1991) are included. IASP91 is a reference model that is a weighted global average with more weight given to subcontinental than to suboceanic regions. Finally, the dotted line represents the SATZ 
Fig. 9. Polar plot of average wavespeeds for $P n$ arrivals, using cubic spline interpolation to generate a continuous curve.

model of Zhao et al. (1999) for southern Africa, but representative of a region to the north of that of the present study. The grey dots show estimates of $P$ wavespeeds from peridotite nodules collected from kimberlite pipes on the Kaapvaal craton, and published by Qiu et al. (1996). BPI1A has upper mantle wavespeeds less than GNEM and SATZ to depths of about 220 and $270 \mathrm{~km}$ respectively, but higher than IASP91 to depths of $270 \mathrm{~km}$. Below $300 \mathrm{~km}$ depth, there is a major discrepancy between SATZ and the other three models, which we believe could be caused by a problem with their method of data analysis (Simon et al., 2002). BPI1A has a discontinuity at $420 \mathrm{~km}$ depth, about $10 \mathrm{~km}$ greater than GNEM or IASP91, and like the other southern African model SATZ, has a rather weakly-defined discontinuity at $660 \mathrm{~km}$. The thickness of the transition zone in BPI1A is $248 \mathrm{~km}$, close to the global average of $241 \mathrm{~km}$ (Flanagan and Shearer, 1998), but the average wavespeeds are slightly higher than in many other regions. In the Eurasian cratonic model GNEM, there is a low wavespeed zone below $220 \mathrm{~km}$ depth, for which there is no evidence in the Kaapvaal data for $P$ waves.

On the right, two $S$ wave models in addition to BPISM are shown: the IASP91 (Kennett, 1991) and QSM96 models (Qiu et al., 1996). The most important features of BPISM are the very high upper mantle wavespeeds to depths of $210 \mathrm{~km}$ compared with IASP91 and the underlying low wavepseed zone. Below $210 \mathrm{~km}$, the wavespeeds cannot be accurately determined, and have been constrained with reference to IASP91, plausible petrological models, and the requirement that the depth of the $410 \mathrm{~km}$ discontinuity agrees with that of the $P$ wave model. Below depths of about $380 \mathrm{~km}$, BPISM lies very close to the reference model IASP91. The other model for the southern African region, QSM96, derived from surface waves to depths of $450 \mathrm{~km}$, has a large low wavespeed zone, which could be a consequence of assuming isotropic wavespeeds in an anisotropic upper man- tle. However, model BPISM, which is representative of the regions off the edges of the Kaapvaal and Zimbabwe cratons requires a low wavespeed zone, but less pronounced and much deeper than in QSM96. The wavespeeds predicted for peridotite xenoliths from kimberlites taken from the paper by Qiu et al. (1996) show somewhat better agreement with BPISM than with their model QSM96.

Model BPISM is similar to the $S$ wave models derived for northern Australia (Dey et al., 1993; Kennett et al., 1994; Kaiho and Kennett, 2000), which is also part of the former supercontinent of Gondwanaland. In particular, the low wavespeed zone is estimated to start at a depth of $210 \mathrm{~km}$ for both regions, suggesting similarity of temperature and possibly composition at these depths. The $S$ wave seismograms of Fig. 7 are also similar to those of figure 6 of Kennett $e t$ al. (1994) with rapid decrease in the amplitudes of the $S$ wave energy travelling above the low wavespeed zone at distances greater than $18^{\circ}$. However, the features of $P$ wave model BPI1A are not like those for northern Australia at depths shallower than $300 \mathrm{~km}$. Furthermore, the $660 \mathrm{~km}$ discontinuity for $P$ waves is more prominent beneath northern Australia than in the present work, or in the adjacent region of southern Africa studied by Zhao et al. (1999).

\section{Discussion}

The average thickness of the crust in the Witwatersrand basin, inferred from receiver functions is about $42 \mathrm{~km}$ (Table 2), which is consistent with the $P n$ and $S n$ travel times from mining-induced events to stations in the southern part of the Kaapvaal craton. This value is also about 4 kilometres greater than the average thickness of the crust in the adjacent regions of the craton: a result that is expected for an intra-cratonic sedimentary basin. However, this thickness of $42 \mathrm{~km}$ is about 6-7 km greater than that inferred by Durrheim and Green (1992) and Durrheim (1998) from recordings of mine tremors along refraction lines deployed 

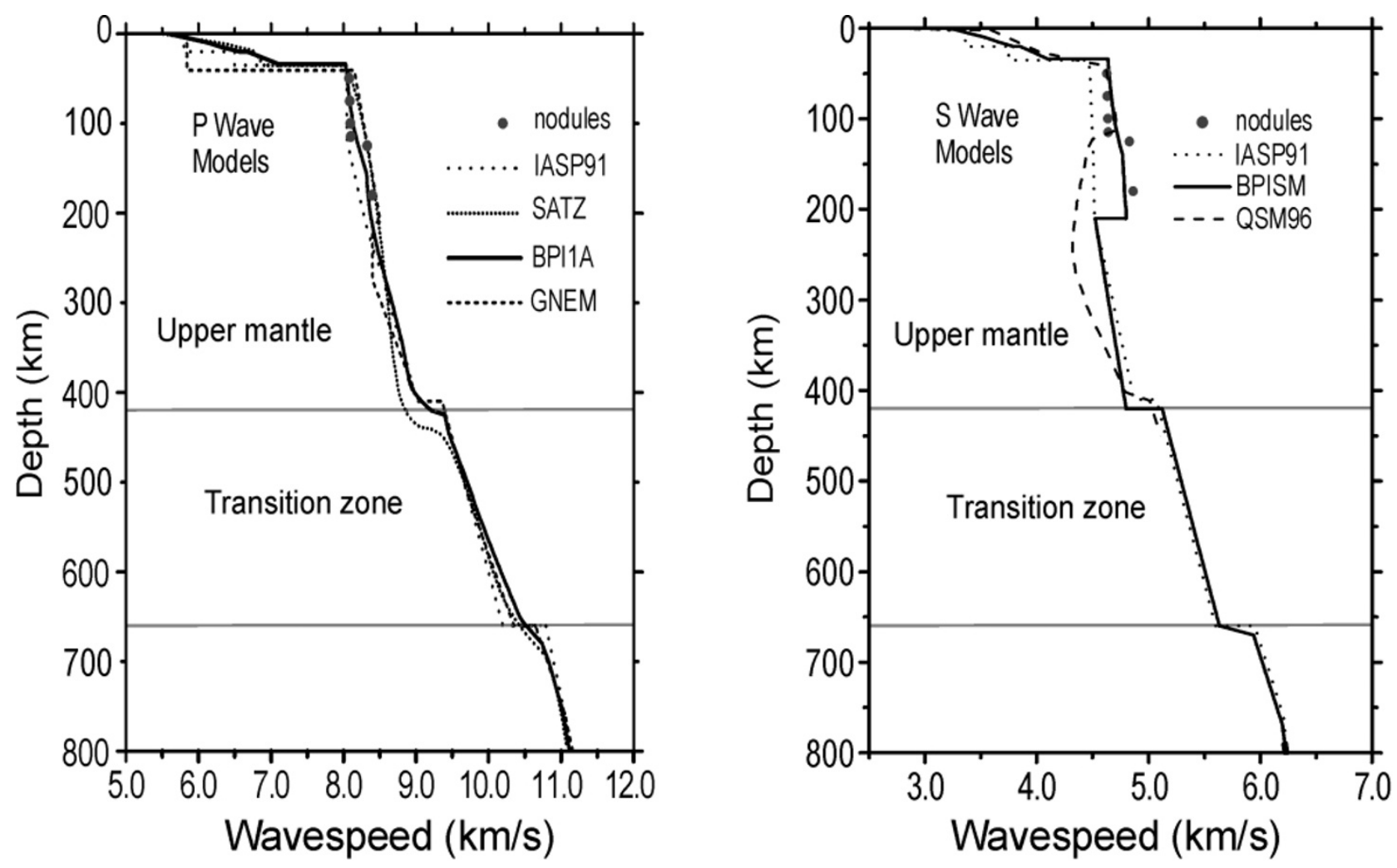

Fig. 10. Left-Comparison of $P$ wavespeed models: IASP91 (Kennett, 1991), SATZ (Zhao et al., 1999), BPI1A and GNEM (Ryberg et al., 1998). The grey circles denote values of $P$ wavespeed for mantle xenoliths estimated by Qiu et al. (1996). Right-Comparison of shear wavespeed models IASP91 (Kennett, 1991), BPISM and QSM96 (Qiu et al., 1996). The grey circles denote values of shear wavespeed for mantle xenoliths estimated by Qiu et al.

across the Witwatersrand basin, though at different locations from the Kaapvaal stations. While the average wavespeeds in the crust are slightly higher in the present work, they do not account for a difference in average thickness of more than a kilometre or so. The present $P$ and $S$ wavespeeds in the uppermost mantle are also higher by about $0.15-0.25$ $\mathrm{km} / \mathrm{s}$ and $0.1 \mathrm{~km} / \mathrm{s}$ respectively, which results in systematically greater estimates of crustal thickness of about $2 \mathrm{~km}$ than in the older work of Durrheim and Green (1992) and Durrheim (1998). Thus, only part of the differences in estimates of crustal thicknesses between the receiver functions and the old refraction results can be explained without examining and comparing phase identifications in the old and new work.

Future work will use tectonic events to complete a full tomographic inversion for the crust and uppermost mantle using the approach of Zhao et al. (1992). The database of seismic events recorded by stations of the Kaapvaal network has been searched for additional earthquakes within or close to the network that have not been listed in existing earthquake catalogues. Over 500 such events have been identified and are being used to complete tomographic inversion and further examine evidence for anisotropy.

The average seismic wavespeeds at greater depths in the mantle for the southern African region are lower (8.08-8.30 $\mathrm{km} / \mathrm{s}$ and $4.67-4.73 \mathrm{~km} / \mathrm{s}$ between depths of 75 and $120 \mathrm{~km}$ respectively) than those resolved by the $P n$ and $S n$ arrivals used in the present work and listed in Table 1 (Simon et al., 2002, 2003; Simon, 2003). The preferred explanation is that the $P n$ and $S n$ arrivals define mantle structure in the central regions of the Kaapvaal craton, where there are highly depleted magnesium-rich perodotites. These central regions may possibly define the original 'shield' defined by de Wit et al. (1992). In contrast, the models for deeper region have been derived from seismic energy that has traversed less depleted peridotites below the margins of the craton and the adjacent mobile belts.

The $P$ and $S$ wave models of the transition zone have a discontinuity at $420 \mathrm{~km}$ depth that is slightly lower, but with a wavespeed contrast that is similar to many other regions. There is no evidence for a discontinuity at $520 \mathrm{~km}$ depth. The differences in frequency content between the high-frequency $P$ and lower-frequency $S$ arrivals result in the $660 \mathrm{~km}$ discontinuity appearing small and transitional rather than sharp for $P$ waves, possibly due to the shorter wavelengths and therefore better resolution of wavespeed gradients (Figs. 6 and 7). However, this is only part of the explanation, since the percentage increase in $S$ wavespeed is greater between depths of 620 and $700 \mathrm{~km}$ (8\% compared with $5 \%$ for $P$ ), which is commonly observed across the $660 \mathrm{~km}$ discontinuity (see, for example, figure 9 of Kennett et al., 1994).

Ringwood (1994) discussed the possible accumulation of subducted former oceanic crust to form a gravitationally stable layer of garnetite some $50 \mathrm{~km}$ thick on top of the $660 \mathrm{~km}$ discontinuity: a process that may have been most effective during the Archaean when mantle temperatures were higher. This would result in an increase in $P$ and $S$ wavespeed gradients towards the base of the transition zone with a possible reduction of the wavespeed jump at the $660 \mathrm{~km}$ discontinuity. The present $P$ wavespeed model with its transitional 660 
$\mathrm{km}$ discontinuity compared with some other regions provides some support for such a process having occurred beneath southern Africa. However, Weidner and Wang (2000) have emphasized that ilmenite-forming transformations could be mistaken for a subducted slab resting on top of the $660 \mathrm{~km}$ discontinuity.

Brudzinski et al. (1997) used seismic profiles to constrain the radial variation in $P$ wavespeed within the transition zone below the northern Philippine Sea. Anomalously high $P$ wavespeeds suggested by tomography were confirmed for a region east of the Ryukyu arc, and lie above the $660 \mathrm{~km}$ discontinuity. The anomaly reduces the $P$ wavespeed contrast locally across the $660 \mathrm{~km}$ discontinuity, and is attributed to a trapped remnant of subducted Pacific lithosphere. This is an example of the reduction in $P$ wavespeed contrast across the $660 \mathrm{~km}$ discontinuity in a modern subduction zone. Intriguing questions concern what happens to the $660 \mathrm{~km}$ discontinuity when subducted material remains trapped in the transition zone over periods of a billion years or more, and what causes the $660 \mathrm{~km}$ discontinuity beneath southern Africa to be lees pronounced than in most other areas.

\section{Conclusions}

Receiver functions and $P n$ and $S n$ arrivals provide a consistent picture of crustal thickness variations in the southern part of the Kaapvaal craton. Both methods show that the crust is much thicker in the northern region affected by the Bushveld magmatic event. $P n$ and $S n$ times, however, indicate a crust in the northern regions of the Kaapvaal craton that is about $7 \mathrm{~km}$ thicker on average than the values estimated from receiver functions. This systematic difference is attributed to the variable elastic properties of mafic rocks that form the lower crust which can change considerably due to differences in metamorphic grade and relatively small changes in composition. This phenomenon can alter the depths of the changes in $S$ wavespeed that cause the main energy conversion from $P$-to- $S V$. The $P n$ and $S n$ arrivals are therefore believed to provide the more reliable estimates of crustal thicknesses. The consequences of this result for assessment of isotasy now need to be examined. Both $P n$ and $S n$ arrival times indicate high seismic wavespeeds at the top of the mantle, implying the presence of highly depleted magnesium-rich peridotites.

Average $P$ and $S$ wavespeed models of the southern African mantle show better agreement with the wavespeeds predicted for peridotite xenoliths than earlier models derived primarily from surface waves. Wavespeeds for $P$ and $S$ are higher than those of IASP91 at depths shallower than 270 and $200 \mathrm{~km}$ respectively. A low wavespeed zone for $S$ below $210 \mathrm{~km}$ depth outside the Kaapvaal craton is clearly identified from the 'shadow zone' resulting from the diminution of $S$ wave arrival amplitudes at greater than $18^{\circ}$. There is a prominent discontinuity at $420 \mathrm{~km}$ depth, associated with the phase transformation from olivine to the $\beta$ phase, but no resolvable discontinuity at $520 \mathrm{~km}$. The average $P$ and $S$ wavespeeds across the transition zone are slightly higher than average and about average respectively. The most interesting result is the identification of a prominent discontinuity for $S$ waves at about $668 \mathrm{~km}$ depth, with a corresponding discontinuity for $P$ waves that is smaller or in- volves increased wavespeed gradients over a comparatively broad depth range. Finally, an insufficient number of regional events of magnitude greater than 5 recorded over the 25-month period of the Kaapvaal experiment has made it difficult to reliably resolve lateral variations in the mantle below depths of $100 \mathrm{~km}$.

Acknowledgments. We thank Dr. David James of the Carnegie Institution of Washington and other members of the Kaapvaal Seismic Group for their assistance in collecting the data used in this project. This work was supported by funding from many different sources: the National Research Foundation, the Council for Geoscience and the University Research Council of the University of the Witwatersrand (South Africa); the National Science Foundation, the Kellogg Foundation, the Mellon Foundation and the U.S. Defense Special Weapons Agency (U.S.A.); the University of Botswana and the Department of Geological Survey (Botswana); and mining companies based in South Africa and Zimbabwe. We are grateful to one of the anonymous reviewers for constructive criticisms that we hope have helped to make the presentation clearer.

\section{References}

Ammon, C. J., The isolation of receiver effects from teleseismic P waveforms, Bull. Seism. Soc. Am., 81, 2504-2510, 1991.

Ben-Ismail, W., G. Barruol, and D. Mainprice, The Kaapvaal craton seismic anisotropy: petrophysical analyses of upper mantle kimberlite nodules, Geophys. Res. Lett., 28, 2497-2500, 2001.

Bloch, S., A. L. Hales, and M. Landisman, Velocities in the crust and upper mantle of southern Africa from multi-mode surface wave dispersion, Bull. Seism. Soc. Am., 59, 1599-1629, 1969.

Brudzinski, M. R., W.-P. Chen, R. L. Nowack, and B.-S. Huang, Variations of $\mathrm{P}$ wave speeds in the mantle transition zone beneath the northern Philippine Sea, J. Geophys. Res., 102, 11,815-11,827, 1997.

Carlson, R. W., T. L. Grove, M. J. de Wit, and J. J. Gurney, Program to study crust and mantle of the Archean craton in southern Africa, Eos, Trans. Am. Geophys. Union, 77(29), 273, 277, 1996.

Chapman, C. H., A new method for computing synthetic seismograms, Geophys. J. R. Astron. Soc., 54, 481-518, 1978.

Cichowicz, A. and R. W. E. Green, Tomographic study of upper mantle structure of the South African continent, using waveform inversion, Phys. Earth Planet. Inter., 72, 276-285, 1992.

De Wit, M. J., C. Roering, R. J. Hart, R. A. Armstrong, C. E. J. Ronde, R. W. E. Green, M. Tredoux, E. Peberdy, and R. A. Hart, Formation of an Archaean continent, Nature, 357, 553-562, 1992.

Dey, S. C., B. L. N. Kennett, J. R. Bowman, and A. Goody, Variations in upper mantle structure under northern Australia, Geophys. J. Int., 114, 304-310, 1993.

Durrheim, R. J., Seismic refraction investigations of the Kaapvaal craton, $S$. African Geophys. Rev., 2, 29-35, 1998.

Durrheim, R. J. and R. W. E. Green, A seismic refraction investigation of the Archaean Kaapvaal craton, South Africa, using mine tremors as the energy source, Geophys. J. Int., 108, 812-832, 1992.

Eales, H. V., A first introduction to the geology of the Bushveld complex, and those aspects of South African geology that relate to it, in Popular Geoscience Series 2, Council for Geoscience, 84 pp., Pretoria, South Africa, 2001.

Flanagan, M. P. and P. M. Shearer, Global mapping of topography on transition zone velocity discontinuities by stacking SS precursors, J. Geophys. Res., 103, 2673-2692, 1998.

Freybourger, M., J. B. Gaherty, T. H. Jordan, and Kaapvaal Seismic Group, Structure of the Kaapvaal craton from surface waves, Geophys. Res. Lett., 28, 2489-2492, 2001.

Gane, P. G., A. L. Hales, and H. O. Oliver, A seismic investigation of the Witwatersrand earth tremors, Bull. Seismol. Soc. Am., 36, 49-80, 1946.

Graham, G. (ed.), Seismological Bulletins (produced monthly), Council for Geoscience, Pretoria, South Africa, April-December issues, 1997.

Graham, G. (ed.), Seismological Bulletins (produced quarterly), Council for Geoscience, Pretoria, South Africa, January-March, April-June, JulySeptember and October-December issues, 1998.

Graham, G. (ed.), Seismological Bulletins (produced quarterly). Council for Geoscience, Pretoria, South Africa, January-March and April-June issues, 1999.

Hales, A. L. and I. S. Sacks, Evidence for an intermediate layer from crustal 
structure studies in the Eastern Transvaal, Geophys. J. R. Astron. Soc., 2, 15-33, 1959.

Hurich, C. A., S. J. Deemer, and A. Indares, Compositional and metamorphic controls on velocity and reflectivity in the continental crust: An example from the Grenville Province of eastern Québec, J. Geophys. Res., 106, 665-682, 2001.

James, D. E., M. J. Fouch, J. C. VanDecar, S. van der Lee, and Kaapvaal Seismic Group, Tectospheric structure beneath southern Africa, Geophys. Res. Lett., 28, 2485-2488, 2001.

Kaiho, K. and B. L. N. Kennett, Three-dimensional seismic structure beneath the Australian region from refracted wave observations, Geophys. J. Int., 142, 651-668, 2000.

Kennett, B. L. N. (ed.), IASPEI 1991 Seismological Tables, 167 pp., Research School of Earth Sciences, Australian National University, Canberra, Australia, 1991.

Kennett, B. L. N., O. Gudmundsson, and C. Tong, The upper mantle S and $\mathrm{P}$ velocity structure beneath northern Australia from broad-band observations, Phys. Earth Planet. Int., 86, 85-98, 1994.

Kgaswane, E. M., C. Wright, M. T. O. Kwadiba, S. J. Webb, and R. G. McRae-Samuel, A new look at South African seismicity using a temporary network of seismometers, S. Afr. J. Sci., 98, 377-384, 2002.

Kwadiba, M. T. O. G., C. Wright, E. M. Kgaswane, R. E. Simon, and T. K. Nguuri, $P n$ arrivals and lateral variations of Moho geometry beneath the Kaapvaal craton, Lithos Special issue: The Slave-Kaapvaal Workshop: A Tale of Two Cratons, edited by A. G. Jones, R. W. Carlson, and H. Grutter, 71, 393-411, 2003.

Nguuri, T. K., J. Gore, D. E. James, S. J. Webb, C. Wright, T. G. Zengeni, O. Gwavava, J. A. Snoke, and Kaapvaal Seismic Group, Crustal structure beneath southern Africa and its implications for the formation and evolution of the Kaapvaal and Zimbabwe cratons, Geophys. Res. Lett., 28, 2501-2504, 2001.

Qiu, X., K. Priestley, and D. McKenzie, Average lithospheric structure of southern Africa, Geophys. J. Int., 127, 563-587, 1996.

Ringwood, A. E., Role of the transition zone and $660 \mathrm{~km}$ discontinuity in mantle dynamics, Phys. Earth Planet. Int., 86, 5-24, 1994.

Rudnick, R. L. and D. W. Fountain, Nature and composition of the continental crust: a lower crustal perspective, Rev. Geophys., 33, 267-309, 1995.

Ryberg, T., F. Wenzel, A. V. Egorkin, and L. Solodilov, Properties of the mantle transition zone in northern Eurasia, J. Geophys. Res., 103, 811$822,1998$.

Schimmel, M. and H. Paulssen, Noise reduction and detection of weak, coherent signals through phase-weighted stacks, Geophys. J. Int., 130, 497-505, 1997.

Silver, P. G., S. S. Gao, K. H. Liu, and the Kaapvaal Seismic Group, Mantle deformation beneath southern Africa, Geophys. Res. Lett., 28, 24932496, 2001.

Simon, R. E., The structure of the upper mantle, transition zone and uppermost lower mantle beneath southern Africa from broad-band seismology,
Ph.D. thesis, 152 pp., University of the Witwatersrand, Johannesburg, 2003.

Simon, R. E., C. Wright, E. M. Kgaswane, and M. T. O. Kwadiba, The P wavespeed structure below and around the Kaapvaal craton to depths of $800 \mathrm{~km}$, from traveltime and waveforms of local and regional earthquakes and mining-induced tremors, Geophys. J. Int., 151, 132-145, 2002.

Simon, R. E., C. Wright, M. T. O. Kwadiba, and E. M. Kgaswane, Mantle structure and composition to $800 \mathrm{~km}$ depth beneath southern Africa and surrounding oceans from broad-band body waves, Lithos Special issue: The Slave-Kaapvaal Workshop: A Tale of Two Cratons, edited by A. G. Jones, R. W. Carlson, and H. Grutter, 71, 353-367, 2003.

Stankiewicz, J., S. Chevrot, R. D. van der Hilst, and M. J. de Wit, Crustal thickness, discontinuity depth, and upper mantle structure beneath southern Africa: constraints from body wave conversions, Phys. Earth Planet. Int., 130, 235-251, 2002.

Walck, M. C., The P wave upper mantle structure beneath an active spreading centre: the Gulf of California, Geophys. J. R. Astr. Soc., 76, 697-723, 1984.

Weidner, D. J. and Y. Wang, Phase transformations: implications for mantle structure, in Earth's Deep Interior. Mineral Physics and Tomography from the Atomic to the Global Scale, edited by S. Karato, A. M. Forte, R. C. Liebermann, G. Masters, and L. Stixrude, pp. 215-235, Geophysical Monograph 117, American Geophysical Union, Washington, D.C., 2000. Willmore, P. L. and A. M. Bancroft, The time-term approach to refraction seismology, Geophys. J. R. Astron. Soc., 3, 419-432, 1960.

Willmore, P. L., A. L. Hales, and P. G. Gane, A seismic investigation of crustal structure in the western Transvaal, Bull. Seismol. Soc. Am., 42, 53-80, 1952.

Wright, C., M. T. O. Kwadiba, E. M. Kgaswane, and R. E. Simon, The structure of the crust and upper mantle to depths of $320 \mathrm{~km}$ beneath the Kaapvaal craton, from $P$ wave arrivals generated by regional earthquakes and mining-induced tremors, J. Afr. Earth Sci., 35, 477-488, 2002.

Wright, C., E. M. Kgaswane, M. T. O. Kwadiba, R. E. Simon, T. K. Nguuri, and R. McRae-Samuel, South African seismicity, April 1997-April 1999, and regional variations in the crust and uppermost mantle of the Kaapvaal craton, Lithos Special issue: The Slave-Kaapvaal Workshop: A Tale of Two Cratons, edited by A. G. Jones, R. W. Carlson, and H. Grutter, 71, 369-392, 2003.

Zhao, D., A. Hasegawa, and S. Horiuchi, Tomographic imaging of P and S wave velocity structure beneath northeastern Japan, J. Geophys. Res., 97, 19909-19928, 1992.

Zhao, M., C. A. Langston, and A. A. Nyblade, Upper mantle velocity structure beneath southern Africa from modeling regional seismic data, J. Geophys. Res., 104, 4783-4794, 1999.

C. Wright (e-mail: cedric.wright@absamail.co.za), M. T. O. Kwadiba, R. E. Simon, E. M. Kgaswane, and T. K. Nguuri 